\title{
Long-term experience with apremilast in patients with psoriatic arthritis: 5-year results from a PALACE 1-3 pooled analysis
}

Arthur Kavanaugh ${ }^{1 * \dagger}$, Dafna D. Gladman ${ }^{2 \dagger}$, Christopher J. Edwards ${ }^{3 \dagger}$, Georg Schett ${ }^{4 \dagger}$, Benoit Guerette ${ }^{5 \dagger}$, Nikolay Delev ${ }^{5+}$, Lichen Teng ${ }^{5+}$, Maria Paris ${ }^{5+}$ and Philip J. Mease ${ }^{6+}$

\begin{abstract}
Background: The efficacy and safety of apremilast were assessed in patients with psoriatic arthritis (PsA) in three phase III clinical trials with similar designs (PALACE 1, 2, and 3).

Methods: Following a 24-week, randomized (1:1:1 to apremilast $30 \mathrm{mg}$ twice daily, $20 \mathrm{mg}$ twice daily, or placebo), double-blind phase and a 28-week blinded active treatment phase, patients could receive apremilast in open-label extension studies for an additional 4 years. Eligible adult patients had active PsA for $\geq 6$ months and three or more swollen joints and three or more tender joints despite prior treatment with disease-modifying anti-rheumatic drugs.

Results: A total of 1493 randomized patients received one or more doses of study medication (placebo: $n=496$; apremilast 30 mg twice daily: $n=497$; apremilast 20 mg twice daily: $n=500$ ). In patients continuing apremilast treatment, response was sustained without new safety issues. At week $260,67.2 \%$ of remaining patients achieved an ACR20 response, and $44.4 \%$ and $27.4 \%$ achieved ACR50 and ACR70 responses, respectively. Among patients with baseline enthesitis and dactylitis, 62.4\% achieved a Maastricht Ankylosing Spondylitis Enthesitis Score of 0 and $80.9 \%$ achieved a dactylitis count of 0 , respectively. In patients who had $\geq 3 \%$ baseline psoriasis body surface area involvement, $43.6 \%$ achieved $\geq 75 \%$ reduction from the baseline Psoriasis Area and Severity Index scores. The most commonly reported adverse events (AEs) were diarrhea, nausea, headache, upper respiratory tract infection, and nasopharyngitis, with most diarrhea and nausea AEs occurring within the first 2 weeks of treatment and usually resolving within 4 weeks. Reported rates of depression during the study were low $(\leq 1.8 \%)$. The majority of patients maintained their weight within $5 \%$ of baseline during the study. No new safety concerns or increases in the incidence or severity of AEs were observed over the long term.
\end{abstract}

Conclusions: Apremilast maintained clinical benefit and a favorable safety profile for up to 5 years among patients with PsA.

Trial registration: ClinicalTrials.gov NCT01172938, NCT01212757, NCT01212770

Keywords: Apremilast, Drug safety, Psoriatic arthritis, Treatment efficacy

\footnotetext{
* Correspondence: akavanaugh@ucsd.edu

${ }^{\dagger}$ Equal contribution.

'School of Medicine, University of California San Diego, 9500 Gilman Drive,

La Jolla, CA 92037, USA

Full list of author information is available at the end of the article
}

(c) The Author(s). 2019 Open Access This article is distributed under the terms of the Creative Commons Attribution 4.0 International License (http://creativecommons.org/licenses/by/4.0/), which permits unrestricted use, distribution, and reproduction in any medium, provided you give appropriate credit to the original author(s) and the source, provide a link to the Creative Commons license, and indicate if changes were made. The Creative Commons Public Domain Dedication waiver (http://creativecommons.org/publicdomain/zero/1.0/) applies to the data made available in this article, unless otherwise stated. 


\section{Introduction}

Apremilast, an oral phosphodiesterase 4 inhibitor, has been proven effective in patients with psoriatic arthritis (PsA) [1-3]. Apremilast was studied for the treatment of PsA in three similarly designed, phase III studies (Psoriatic Arthritis Long-term Assessment of Clinical Efficacy [PALACE] 1, 2, and 3) that enrolled disease-modifying anti-rheumatic drug (DMARD)-experienced patients [1-3]. These studies included an open-label extension phase to evaluate the effects of long-term exposure to apremilast. We now report the final long-term findings for PALACE 1 , 2 , and 3 in patients with active PsA who received apremilast for up to 260 weeks.

\section{Methods}

\section{Study design}

PALACE 1, 2, and 3 were phase III, multicenter, randomized, double-blind, placebo-controlled studies. The three studies used the same study design and have been previously described [1-3]. Briefly, each study comprised a 24-week, randomized, double-blind, placebo-controlled phase; a 28-week blinded active treatment phase; and a long-term, open-label extension phase for up to an additional 4 years. Patients were randomly assigned at baseline (1:1:1) to receive placebo, apremilast $30 \mathrm{mg}$ twice daily, or apremilast $20 \mathrm{mg}$ twice daily. Patients randomized to placebo were re-randomized to apremilast $30 \mathrm{mg}$ twice daily or $20 \mathrm{mg}$ twice daily at week 16 (early escape) or week 24. Patients who completed 52 weeks of treatment were eligible to enroll in the long-term extension for apremilast treatment for an additional 4 years.

\section{Patients}

As previously described, patients were adults with active PsA for $\geq 6$ months who met the Classification Criteria for Psoriatic Arthritis (CASPAR) [4] and had three or more swollen joints and three or more tender joints despite prior exposure to conventional or biologic DMARDs [1-3]. Patients enrolled in PALACE 3 also had active skin disease with at least one plaque psoriasis lesion that was $\geq 2 \mathrm{~cm}$ in size [3].

\section{Study outcomes}

\section{Efficacy assessments}

Efficacy endpoints included rates of patients achieving $\geq 20 \%$ improvement in American College of Rheumatology response criteria (ACR20) (primary endpoint), ACR50, and ACR70 responses, modified for PsA using the 76 swollen joint count (SJC) and 78 tender joint count (TJC) (i.e., inclusion of distal interphalangeal joints of the toes and carpometacarpal joints to total joint counts) [5, 6]; changes from baseline in SJC and TJC; proportions of patients achieving a Maastricht Ankylosing Spondylitis Enthesitis Score (MASES) [7] of 0 among those with enthesitis at baseline, and proportions of patients achieving a dactylitis count of 0 among those with dactylitis at baseline. Physical function assessments included mean change from baseline and achievement of a minimal clinically important difference (MCID) of $\geq$ 0.35 [8] in the Health Assessment Questionnaire-Disability Index (HAQ-DI) score [9]. Skin involvement was also assessed using $\geq 75 \%$ reduction from the baseline Psoriasis Area and Severity Index (PASI-75) in patients with psoriasis involving $\geq 3 \%$ of body surface area at baseline.

\section{Safety assessments}

Safety assessments were conducted at scheduled visits during each treatment phase and in the event of early termination/withdrawal and included collection of adverse events (AEs) as well as physical examination and clinical laboratory findings. The AEs occurring after randomization were classified using the Medical Dictionary for Drug Regulatory Activities Classification System.

\section{Statistical analyses}

Data were pooled across the three studies. Efficacy data were analyzed descriptively by time point using all available data; analyses through week 260 were based on observed data without imputation for missing data. Safety outcomes were analyzed descriptively for all patients who received one or more doses of apremilast and are presented for the apremilast-exposure periods from weeks 0 to $\leq 52$ (relative to the first dose of apremilast), weeks $>52$ to $\leq 104$, weeks $>104$ to $\leq 156$, weeks $>156$ to $\leq 208$, and weeks $>208$.

\section{Results}

\section{Patients}

Across PALACE 1-3, 1493 patients were randomized and received one or more doses of study medication (placebo: $n=496$; apremilast $30 \mathrm{mg}$ twice daily: $n=497$; apremilast $20 \mathrm{mg}$ twice daily: $n=500$ ). Baseline patient demographic and disease characteristics have been previously described [1-3] and were comparable across treatment groups. Among patients randomized to apremilast $30 \mathrm{mg}$ or $20 \mathrm{mg}$ at baseline, $44.5 \%(221 / 497)$ and $42.4 \%(212 / 500)$ completed week 260, respectively. Among patients randomized to placebo at baseline and switched to apremilast $30 \mathrm{mg}$ or $20 \mathrm{mg}$ at week 16 or 24 , $49.1 \%(110 / 224)$ and $41.8 \%(92 / 220)$ completed week 260 , respectively. Of those who received apremilast 30 $\mathrm{mg}$ or $20 \mathrm{mg}$ entering week 52 , regardless of when initiated (baseline, week 16, or week 24), 63.2\% (331/524) and $58.7 \%$ (304/518) completed 260 weeks, respectively. A total of 684 patients had $>208$ weeks of exposure to apremilast (20 mg, $n=320 ; 30 \mathrm{mg}, n=364$ ). Over the apremilast-exposure period, the most commonly cited 
reasons for study discontinuation were withdrawal of consent by patient (18.0\%), lack of efficacy (17.6\%), and adverse event (11.9\%). Other reasons for discontinuation included lost to follow-up (2.6\%), non-compliance (1.2\%), protocol violation $(0.6 \%)$, death $(0.5 \%)$, and "other" (3.3\%).

\section{Efficacy outcomes}

Of patients receiving apremilast $30 \mathrm{mg}$ twice daily, 55.3\% achieved an ACR20 response at week 52; at week 260, $67.2 \%$ of patients who continued apremilast treatment achieved an ACR20 response. Similarly, ACR50 and ACR70 responses were sustained over 260 weeks with continued treatment (Fig. 1, Additional file 1: Table S1). Mean SJC and TJC improved by $63.3 \%$ and $49.8 \%$ at week 52, with improvements reaching $82.3 \%$ and $72.7 \%$, respectively, with continued treatment at week 260 (Fig. 2, Additional file 1: Table S1).

Among patients with enthesitis or dactylitis at baseline, mean changes in MASES and dactylitis at week 260 were -2.9 and -2.8 , respectively. The proportions of those achieving a MASES of 0 or a dactylitis count of 0 increased over 52 weeks and were maintained through week 260 with continued apremilast $30 \mathrm{mg}$ treatment (Fig. 3, Additional file 1: Table S1).

Improvements in physical function were maintained through week 260 in patients who continued receiving apremilast $30 \mathrm{mg}$ twice daily, including mean change in HAQ-DI and the proportion achieving a HAQ-DI MCID $\geq 0.35$ (Fig. 4, Additional file 1: Table S1).

Among patients with plaque psoriasis involving $\geq 3 \%$ of the body surface area at baseline, the proportion of patients achieving PASI-75 response was generally maintained with continued treatment, with $43.6 \%$ of patients having a PASI-75 response at week 260 (Additional file 1: Figure S1 and Additional file 1: Table S1).

Pooled results for apremilast $30 \mathrm{mg}$ twice daily were consistent with the results observed in the individual studies for all outcomes, including ACR20 responses (Additional file 1: Figure S2). Apremilast $20 \mathrm{mg}$ twice daily also demonstrated improvements in the signs and symptoms of PsA (Additional file 1: Table S1).

\section{Safety outcomes}

Most AEs were mild or moderate in severity with both apremilast doses over weeks 0 to $\leq 52$. During weeks 0 to $\leq 52$, AEs occurring in $\geq 5 \%$ of apremilast-exposed patients included diarrhea, nausea, headache, upper respiratory tract infection, and nasopharyngitis. Most diarrhea and nausea AEs were reported within the first 2 weeks of treatment and usually resolved within 4 weeks; the frequency of gastrointestinal AEs decreased with longer apremilast exposure, and the frequency of other common AEs decreased or remained stable with prolonged exposure (Table 1).

No new safety concerns or increases in the incidence or severity of AEs were seen with exposure over 260 weeks (Table 1). Discontinuations due to AEs during weeks 0 to $\leq 52$ occurred in $7.6 \%$ of combined apremilast patients. In the longer exposure periods, $\leq 2.5 \%$ of patients discontinued treatment because of AEs. The most frequently reported AEs leading to discontinuation of apremilast were diarrhea, nausea, and headache and were primarily reported during the 0 - to $\leq 52$-week period (Table 2).

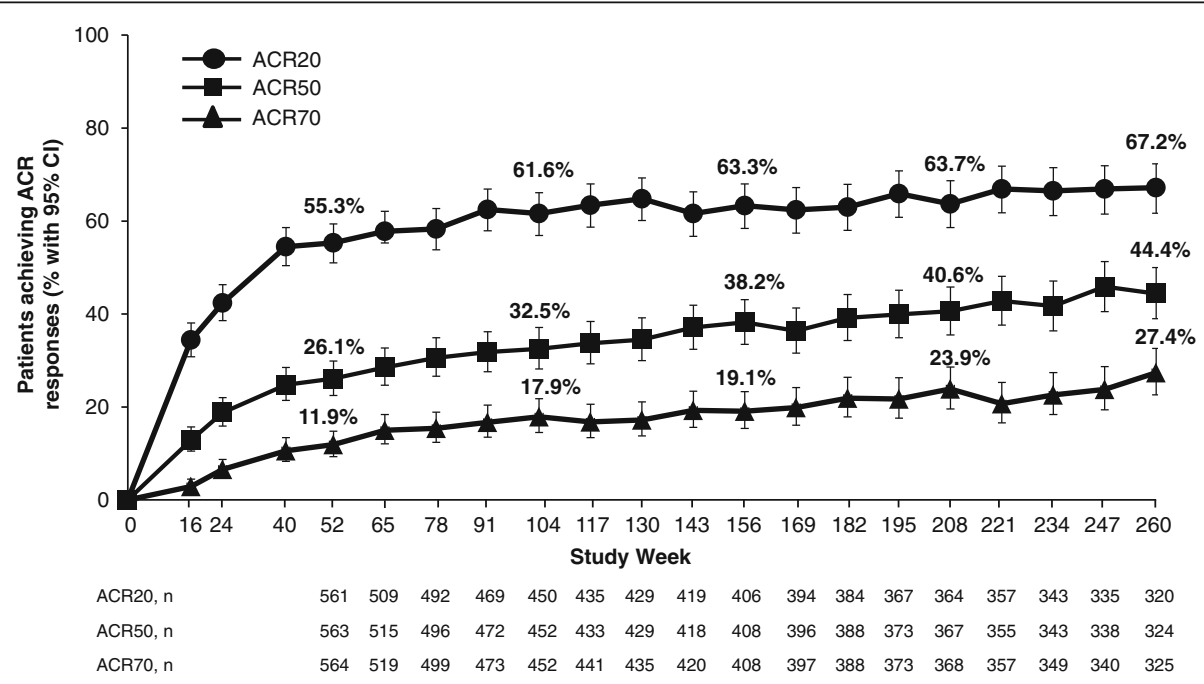

Fig. 1 ACR responses in PSA patients receiving apremilast $30 \mathrm{mg}$ up to 260 weeks. Data as observed. The analysis includes all patient data, including the placebo-controlled phase, regardless of when the patients started taking apremilast (baseline, week 16, or week 24). The proportions of psoriatic arthritis (PSA) patients achieving ACR20, ACR50, or ACR70 responses at study visits up to week 260 are shown. Error bars represent $95 \%$ confidence interval $(C \mathrm{Cl}) . n$ represents the number of patients with data available at that time point 


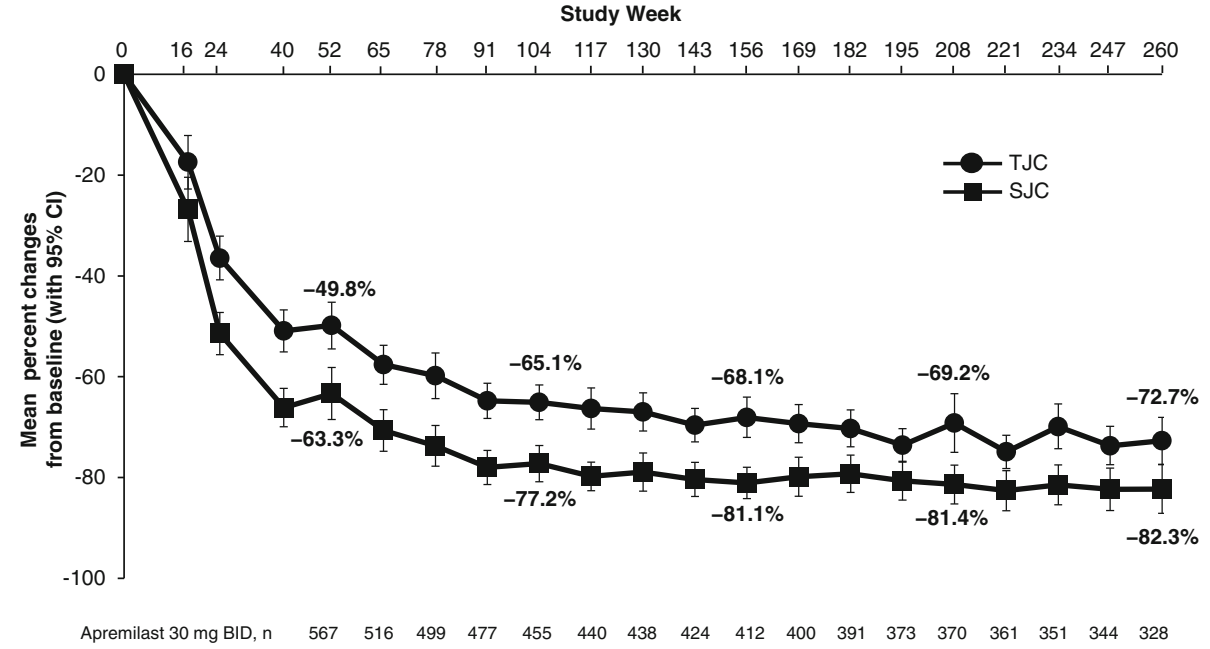

Fig. $2 \mathrm{SJC} / T$ JC improvements in PSA patients receiving apremilast $30 \mathrm{mg}$ up to 260 weeks. Data as observed. The analysis includes all patient data, including the placebo-controlled phase, regardless of when the patients started taking apremilast (baseline, week 16, or week 24). The mean percentage changes in swollen joint count (SJC) and tender joint count (TJC) for psoriatic arthritis (PsA) patients at study visits up to week 260 are shown. Error bars represent $95 \%$ confidence interval $(\mathrm{Cl}) . n$ represents the number of patients with data available at that time point

Serious AEs occurred at low and similar rates $(\leq 8.4 \%$ of combined apremilast patients) during each of the five apremilast-exposure periods. Infections and infestations and musculoskeletal and connective tissue disorders were the most common classes of serious AE. Each was reported in $\leq 1.8 \%$ of combined apremilast patients during each apremilast-exposure period. During the placebo-controlled period, rates of major cardiac events, malignant neoplasms, and serious opportunistic infections were comparable between placebo and apremilast
[1-3]. There was no increase in overall rates with longer-term exposure.

In the placebo-controlled period, reports of depression were rare but greater with apremilast compared with placebo ( $1.2 \%$ vs $0.8 \%)$. Rates of depression during the long-term study were low with combined rates of $1.7 \%$, $1.8 \%, 1.5 \%, 1.6 \%$, and $1.0 \%$ for apremilast reported across the five periods examined. No completed suicides occurred during the study. Attempted suicide was reported by one patient during the weeks 0 to $\leq 52$

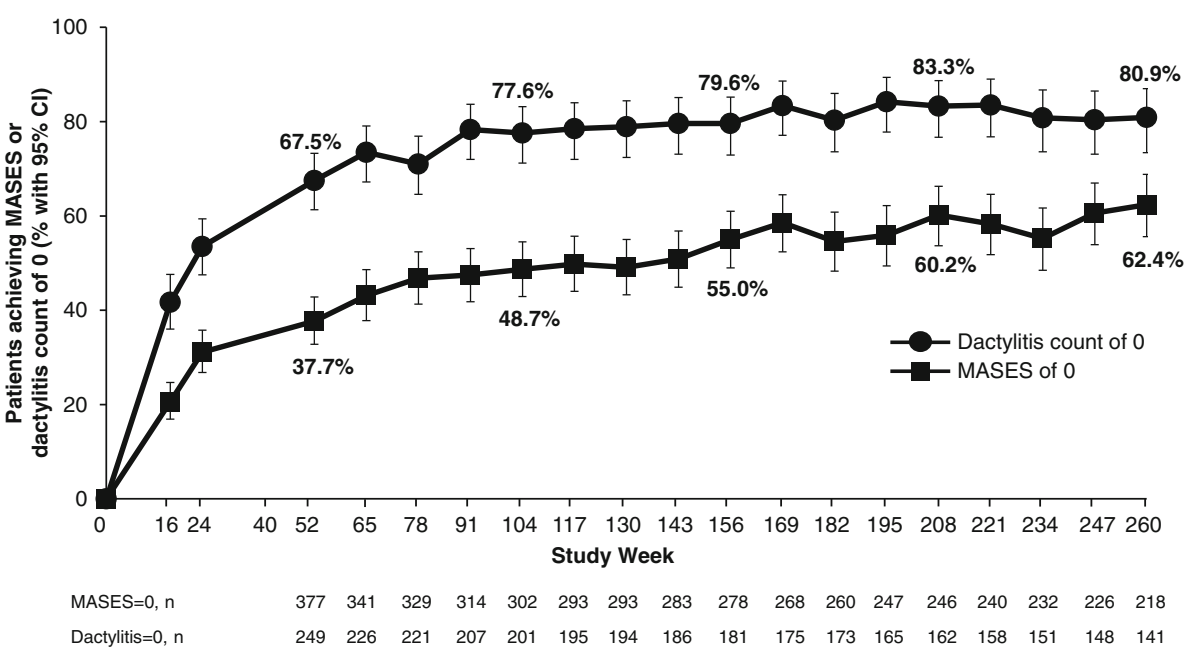

Fig. 3 Enthesitis/dactylitis improvements in PsA patients receiving apremilast $30 \mathrm{mg}$ up to 260 weeks. Data as observed. The analysis includes all patient data, including the placebo-controlled phase, regardless of when the patients started taking apremilast (baseline, week 16, or week 24). The proportions of patients achieving a Maastricht Ankylosing Spondylitis Enthesitis Score (MASES) of 0 ( $>0$ indicating enthesitis) or a dactylitis count of 0 at study visits up to week 260 are shown. Error bars represent $95 \%$ confidence interval $(\mathrm{Cl})$. $n$ represents the number of patients with either MASES $\geq 1$ or dactylitis count $\geq 1$ at baseline and data available at that time point 


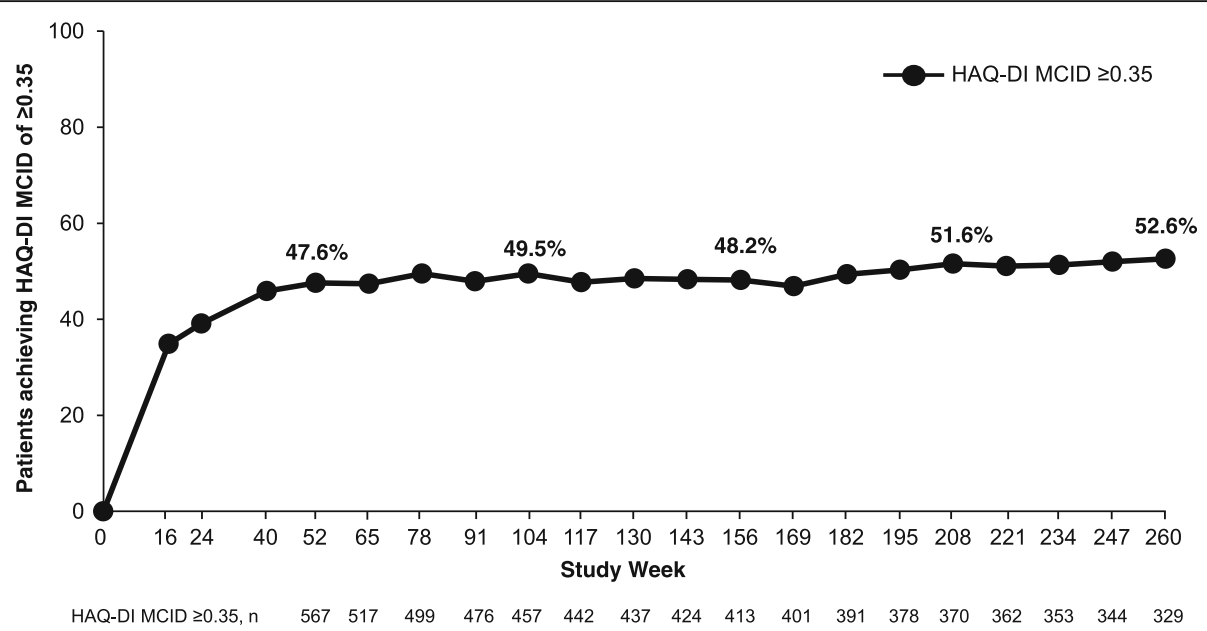

Fig. 4 Improvements in physical function among PSA patients receiving apremilast $30 \mathrm{mg}$ up to 260 weeks. Data as observed. The analysis includes all patient data, including the placebo-controlled phase, regardless of when the patients started taking apremilast (baseline, week 16, or week 24). The proportions of patients achieving a Health Assessment Questionnaire-Disability Index (HAQ-DI) minimal clinically important difference (MCID) of $\geq 0.35$ at study visits up to week 260 are shown. $n$ represents the number of patients with data available at that time point

apremilast-exposure period (following a serious family altercation) and one patient during the weeks $>52$ to $\leq 104$ apremilast-exposure period (history of depression, bipolar affective disorder, physical/emotional abuse). No suicide attempts were reported during the remaining apremilast-exposure periods. The ranges of mean (median) weight changes were between $-1.34 \mathrm{~kg}(-1.00 \mathrm{~kg})$ and $-0.92 \mathrm{~kg}(-0.90 \mathrm{~kg})$ with apremilast $30 \mathrm{mg}$ and $1.36 \mathrm{~kg}(-1.00 \mathrm{~kg})$ and $-0.98 \mathrm{~kg}(-0.40 \mathrm{~kg})$ with apremilast $20 \mathrm{mg}$ across exposure periods, with the majority of patients maintaining their weight within $5 \%$ of baseline during the study. Weight loss $>5 \%$ was observed in $21.8 \%$ (155/711) of apremilast $30 \mathrm{mg}$ patients and 21.0\% (149/708) of apremilast $20 \mathrm{mg}$ patients. Clinically important laboratory abnormalities were generally infrequent, transient, and of similar incidence during all periods (Table 1). Throughout the longer-term apremilast-exposure periods, the majority of patients with normal baseline values for laboratory parameters evaluated continued to maintain values within the normal range (Additional file 1: Table S2).

\section{Discussion}

In one of the largest cohorts of patients with active PsA, treatment with apremilast was evaluated for up to 5 years in the phase III PALACE 1, 2, and 3 studies. More than $40 \%$ of patients continued apremilast treatment in the long-term extension studies through 260 weeks.

During the long-term open-label extension phases of these studies, the population of patients who continued apremilast treatment for 5 years maintained improvements in signs and symptoms of PsA, including SJC, TJC, and physical function. Enthesitis, dactylitis, and psoriasis were also improved in patients with these manifestations at baseline. Given that one third of patients remaining on treatment at week 260 did not achieve an ACR20 response, results suggest using outcome measures other than ACR20 response criteria when evaluating PsA disease activity. In a separate study characterizing the clinical benefits associated with long-term apremilast treatment in patients who did not achieve an ACR20 response at week 104, significant improvements in core psoriatic domains were observed despite the ACR20 non-response $[10,11]$. Taken together, this may explain why patients who fail to achieve an ACR20 response continue on long-term apremilast treatment.

Apremilast continued to demonstrate a favorable safety profile in patients with active PsA who were previously treated with a DMARD and/or biologic therapies. The rates and types of AEs were consistent throughout the three PALACE studies, and no new safety signals were observed across 5 years of apremilast treatment.

A limitation of these studies is that the impact of apremilast on structural disease progression was not assessed in the PALACE clinical trial program. Importantly, the results from this analysis indicated significant improvements in the numbers of swollen and tender joints over 5 years of treatment. Given that improvements in joint inflammation have been associated with the prevention of structural damage [12], it is possible that high levels of disease control among patients in the PALACE 1-3 studies may have been associated with inhibition of disease progression. A limitation of controlled clinical studies is the enrollment of patients with restricted eligibility criteria, which may not represent the general population of patients with PsA. Additionally, although open-label extensions offer insight into the experience with a given treatment in the population of patients who do remain on therapy over the long term, efficacy results may be 


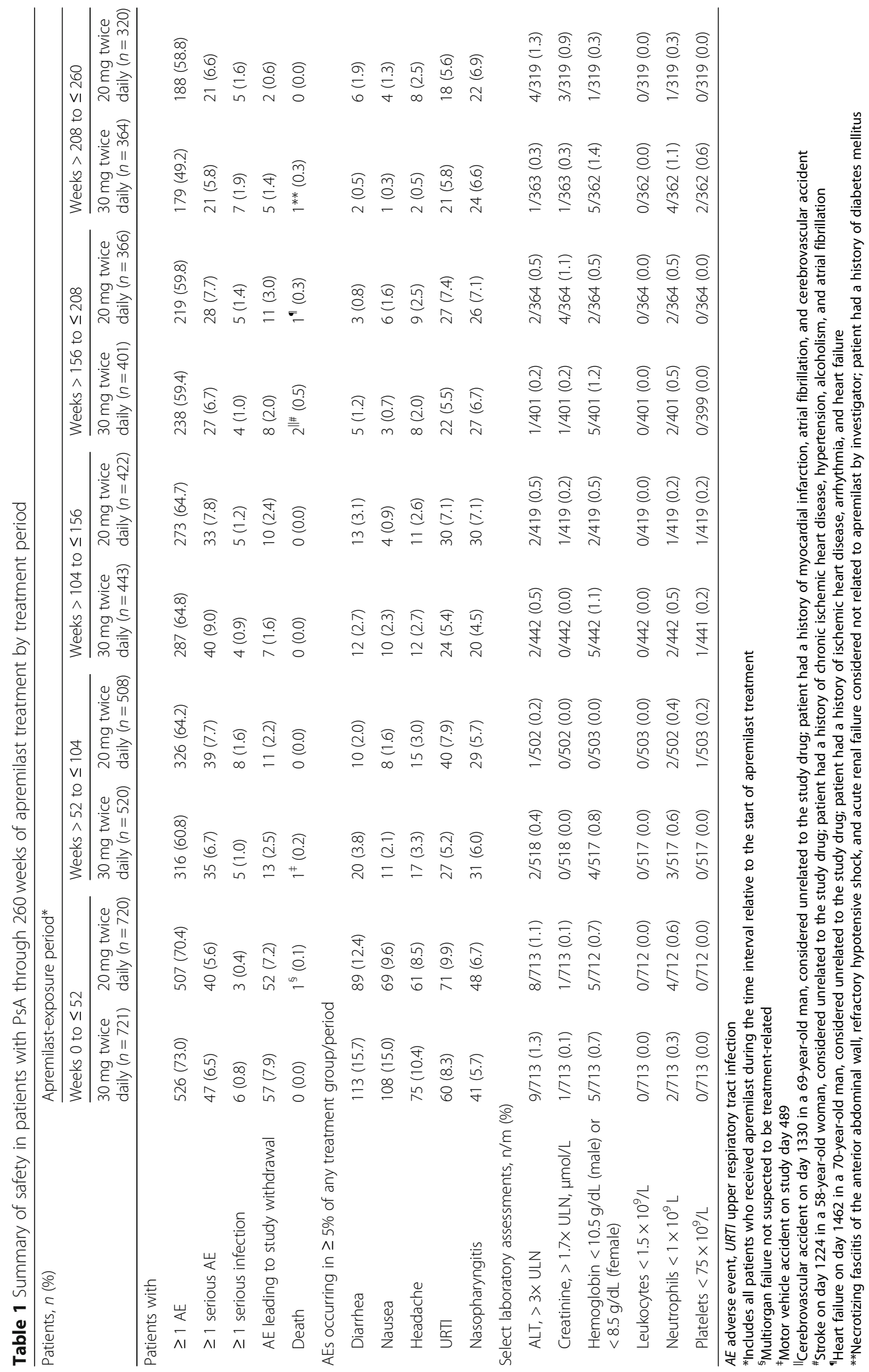


Table 2 Adverse events leading to discontinuation in $>2$ patients in any single exposure period through 260 weeks of apremilast treatment by treatment period

\begin{tabular}{|c|c|c|c|c|c|c|c|c|c|c|}
\hline \multirow[t]{3}{*}{ Patients, $n(\%)$} & \multicolumn{10}{|c|}{ Apremilast-exposure period* } \\
\hline & \multicolumn{2}{|c|}{ Weeks 0 to $\leq 52$} & \multicolumn{2}{|c|}{ Weeks $>52$ to $\leq 104$} & \multicolumn{2}{|c|}{ Weeks $>104$ to $\leq 156$} & \multicolumn{2}{|c|}{ Weeks $>156$ to $\leq 208$} & \multicolumn{2}{|c|}{ Weeks $>208$ to $\leq 260$} \\
\hline & $\begin{array}{l}30 \mathrm{mg} \\
\text { twice daily } \\
(n=721)\end{array}$ & $\begin{array}{l}20 \mathrm{mg} \\
\text { twice daily } \\
(n=720)\end{array}$ & $\begin{array}{l}30 \mathrm{mg} \\
\text { twice daily } \\
(n=520)\end{array}$ & $\begin{array}{l}20 \mathrm{mg} \\
\text { twice daily } \\
(n=508)\end{array}$ & $\begin{array}{l}30 \mathrm{mg} \\
\text { twice daily } \\
(n=443)\end{array}$ & $\begin{array}{l}20 \mathrm{mg} \\
\text { twice daily } \\
(n=422)\end{array}$ & $\begin{array}{l}30 \mathrm{mg} \\
\text { twice daily } \\
(n=401)\end{array}$ & $\begin{array}{l}20 \mathrm{mg} \\
\text { twice daily } \\
(n=366)\end{array}$ & $\begin{array}{l}30 \mathrm{mg} \\
\text { twice daily } \\
(n=364)\end{array}$ & $\begin{array}{l}20 \mathrm{mg} \\
\text { twice daily } \\
(n=320)\end{array}$ \\
\hline Nausea & $16(2.2)$ & $8(1.1)$ & $0(0.0)$ & $0(0.0)$ & $0(0.0)$ & $0(0.0)$ & $0(0.0)$ & $0(0.0)$ & $0(0.0)$ & $0(0.0)$ \\
\hline Diarrhea & $15(2.1)$ & $6(0.8)$ & $1(0.2)$ & $0(0.0)$ & $0(0.0)$ & $1(0.2)$ & $0(0.0)$ & $0(0.0)$ & $1(0.3)$ & $0(0.0)$ \\
\hline Headache & $11(1.5)$ & $4(0.6)$ & $0(0.0)$ & $0(0.0)$ & $1(0.2)$ & $0(0.0)$ & $0(0.0)$ & $0(0.0)$ & $0(0.0)$ & $0(0.0)$ \\
\hline Vomiting & $6(0.8)$ & $1(0.1)$ & $0(0.0)$ & $0(0.0)$ & $0(0.0)$ & $0(0.0)$ & $0(0.0)$ & $0(0.0)$ & $0(0.0)$ & $0(0.0)$ \\
\hline Dizziness & $4(0.6)$ & $2(0.3)$ & $0(0.0)$ & $0(0.0)$ & $0(0.0)$ & $0(0.0)$ & $0(0.0)$ & $0(0.0)$ & $0(0.0)$ & $0(0.0)$ \\
\hline $\begin{array}{l}\text { Upper } \\
\text { abdominal } \\
\text { pain }\end{array}$ & $3(0.4)$ & $4(0.6)$ & $0(0.0)$ & $0(0.0)$ & $0(0.0)$ & $0(0.0)$ & $0(0.0)$ & $1(0.3)$ & $0(0.0)$ & $0(0.0)$ \\
\hline Migraine & $3(0.4)$ & $1(0.1)$ & $0(0.0)$ & $0(0.0)$ & $0(0.0)$ & $0(0.0)$ & $0(0.0)$ & $0(0.0)$ & $0(0.0)$ & $0(0.0)$ \\
\hline Fatigue & $3(0.4)$ & $2(0.3)$ & $0(0.0)$ & $0(0.0)$ & $0(0.0)$ & $0(0.0)$ & $0(0.0)$ & $1(0.3)$ & $0(0.0)$ & $0(0.0)$ \\
\hline
\end{tabular}

*Includes all patients who received apremilast during the time interval relative to the start of apremilast treatment

biased by the discontinuation of patients due to the lack or loss of response and absence of a control arm. Emerging real-world evidence will provide more insight into the use and effectiveness of apremilast in clinical practice.

\section{Conclusions}

In this pooled analysis of three long-term extension studies, apremilast continued to demonstrate a favorable safety profile, with no new safety concerns identified, and was generally well tolerated for up to 5 years. Patients who continued therapy demonstrated sustained, clinically meaningful improvements in the signs and symptoms across various domains of PsA as well as in physical function.

\section{Additional file}

Additional file 1: Figure S1. PASI-75 response in PSA patients receiving apremilast $30 \mathrm{mg}$ twice daily up to 260 weeks. Figure S2. ACR20 responses in PsA patients receiving apremilast $30 \mathrm{mg}$ twice daily up to 260 weeks across PALACE studies. Table S1. Efficacy outcomes at week 260 in patients with PsA treated with apremilast. Table S2. Clinically important shifts in select laboratory measurements among patients with normal values at baseline. (DOCX $117 \mathrm{~kb})$

\section{Abbreviations}

AE: Adverse event; DMARD: Disease-modifying anti-rheumatic drug; HAQDI: Health Assessment Questionnaire-Disability Index; MASES: Maastricht Ankylosing Spondylitis Enthesitis Score; PALACE: Psoriatic Arthritis Long-term Assessment of Clinical Efficacy; PASI-75: $\geq 75 \%$ reduction from the baseline Psoriasis Area and Severity Index score; PsA: Psoriatic arthritis; SJC: Swollen joint count; TJC: Tender joint count

\section{Acknowledgements}

The authors received editorial support in the preparation of this report from Kristin Carlin, RPh, MBA, of Peloton Advantage, LLC, an OPEN Health company, Parsippany, NJ, USA, funded by Celgene Corporation, Summit, NJ,
USA, and from Julia R. Gage, PhD, of Gage Medical Writing, LLC, Moorpark, CA, USA, on behalf of Peloton Advantage. The authors, however, directed and are fully responsible for all content and editorial decisions for this report.

Funding

This study was sponsored by Celgene Corporation.

\section{Availability of data and materials}

Celgene is committed to responsible and transparent sharing of clinical trial data with patients, healthcare practitioners, and independent researchers for the purpose of improving scientific and medical knowledge as well as fostering innovative treatment approaches. For more information, please visit https://www.celgene.com/research-development/clinical-trials/clinical-trialsdata-sharing/.

\section{Authors' contributions}

DDG contributed to the pooled analysis concept and design of the study. $B G, N D, L T$, and $M P$ contributed to the data acquisition and preparation. $A K$, $\mathrm{DDG}, \mathrm{CJE}, \mathrm{GS}, \mathrm{BG}, \mathrm{ND}, \mathrm{LT}, \mathrm{MP}$, and PJM contributed to the data analysis and interpretation and manuscript review. All authors read and approved the final manuscript.

Ethics approval and consent to participate

The institutional review boards from each participating medical center approved the study protocol for each of the three studies. All patients provided written informed consent before any study-related procedures were conducted.

\section{Consent for publication}

Not applicable.

\section{Competing interests}

AK has received grant/research support from Abbott, Amgen, AstraZeneca, BMS, Celgene Corporation, Centocor-Janssen, Pfizer, Roche, and UCB. DDG has received grant/research support from and served as a consultant for AbbVie, Amgen, BMS, Celgene Corporation, Gilead, Janssen, Novartis, Pfizer, and UCB. CJE has received grant/research support from and served as a consultant for AbbVie, BMS, Celgene Corporation, Janssen, Pfizer, Roche, Samsung, Sanofi, and UCB. GS has received grant/research support from and served as a consultant for Abbott, Celgene Corporation, Roche, and UCB. BG, ND, LT, and MP are employees of Celgene Corporation. PJM has received grant/research support from and served as a consultant for Abbott, Amgen, Biogen Idec, BMS, Celgene Corporation, Eli Lilly, Genentech, Janssen, Novartis, Pfizer, and UCB, and has served on speakers bureaus for Abbott, Amgen, Biogen Idec, BMS, Eli Lilly, Genentech, Janssen, Pfizer, and UCB. 


\section{Publisher's Note}

Springer Nature remains neutral with regard to jurisdictional claims in published maps and institutional affiliations.

\section{Author details}

'School of Medicine, University of California San Diego, 9500 Gilman Drive, La Jolla, CA 92037, USA. ²Division of Rheumatology, Krembil Research Institute, Toronto Western Hospital, University of Toronto, Toronto, Ontario, Canada. ${ }^{3} \mathrm{NIHR}$ Wellcome Trust Clinical Research Facility, University Hospital Southampton, Southampton, UK. ${ }^{4}$ Friedrich-Alexander-Universität Erlangen-Nürnberg und Universitätsklinikum Erlangen, Erlangen, Germany. ${ }^{5}$ Celgene Corporation, Summit, NJ, USA. ${ }^{6}$ Rheumatology Clinical Research Division, Swedish Medical Center/Providence St. Joseph Health and University of Washington, Seattle, WA, USA.

Received: 12 December 2018 Accepted: 18 April 2019

Published online: 10 May 2019

\section{References}

1. Kavanaugh A, Mease PJ, Gomez-Reino JJ, Adebajo AO, Wollenhaupt J, Gladman DD, et al. Treatment of psoriatic arthritis in a phase 3 randomized, placebo-controlled trial with apremilast, an oral phosphodiesterase 4 inhibitor. Ann Rheum Dis. 2014;73(6):1020-6.

2. Cutolo M, Myerson GE, Fleischmann R, Liote F, Diaz-Gonzalez F, Van den Bosch $F$, et al. A phase III, randomized, controlled trial of apremilast in patients with psoriatic arthritis: results of the PALACE 2 trial. J Rheumatol. 2016:43(9):1724-34.

3. Edwards CJ, Blanco FJ, Crowley J, Birbara CA, Jaworski J, Aelion J, et al. Apremilast, an oral phosphodiesterase 4 inhibitor, in patients with psoriatic arthritis and current skin involvement: a phase III, randomised, controlled trial (PALACE 3). Ann Rheum Dis. 2016;75(6):1065-73.

4. Taylor W, Gladman D, Helliwell P, Marchesoni A, Mease P, Mielants H. Classification criteria for psoriatic arthritis: development of new criteria from a large international study. Arthritis Rheum. 2006;54(8):2665-73.

5. Felson DT, Anderson JJ, Boers M, Bombardier C, Furst D, Goldsmith C, et al. American College of Rheumatology. Preliminary definition of improvement in rheumatoid arthritis. Arthritis Rheum. 1995:38(6):727-35.

6. El Miedany Y. Recent developments in management of psoriatic arthritis Curr Rheumatol Rev. 2005;1(1):9-19.

7. Heuft-Dorenbosch L, Spoorenberg A, van Tubergen A, Landewe R, van ver Tempel $H$, Mielants $H$, et al. Assessment of enthesitis in ankylosing spondylitis. Ann Rheum Dis. 2003;62(2):127-32.

8. Mease PJ, Woolley JM, Bitman B, Wang BC, Globe DR, Singh A. Minimally important difference of health assessment questionnaire in psoriatic arthritis: relating thresholds of improvement in functional ability to patientrated importance and satisfaction. J Rheumatol. 2011:38(11):2461-5.

9. Fries JF, Spitz PW, Young DY. The dimensions of health outcomes: the health assessment questionnaire, disability and pain scales. J Rheumatol. 1982;9(5):789-93.

10. Mease P, Gladman D, Kavanaugh A, Nakasato P, Guerette B, Teng L, et al. Characterization of clinical benefits in subjects classified as ACR20 nonresponders at week 104 of apremilast treatment: subanalysis of 3 long-term, phase III trials [abstract OP0309]. Ann Rheum Dis. 2018;77(Suppl 2):201-2.

11. Mease PJ, Gladman DD, Kavanaugh A, Nakasato P, Guerette B, Teng L, et al. Characterization of clinical benefits in subjects classified as ACR20 nonresponders at week 104 of apremilast treatment: subanalysis of 3 long-term, phase III trials [abstract]. Arthritis Rheumatol. 2017;69(Suppl 10):603.

12. Gladman DD, Farewell VT, Nadeau C. Clinical indicators of progression in psoriatic arthritis: multivariate relative risk model. J Rheumatol. 1995;22(4): 675-9.

Ready to submit your research? Choose BMC and benefit from:

- fast, convenient online submission

- thorough peer review by experienced researchers in your field

- rapid publication on acceptance

- support for research data, including large and complex data types

- gold Open Access which fosters wider collaboration and increased citations

- maximum visibility for your research: over $100 \mathrm{M}$ website views per year

At $\mathrm{BMC}$, research is always in progress.

Learn more biomedcentral.com/submissions 